\title{
Activatable Fluorescence Imaging and Targeted Drug Delivery via Extracellular Vesicle- like Porous Coordination Polymer Nanoparticles
}

Yafeng Wu, Fen Zhang, Kan Wang, Peicheng Luo, Yuanqing Wei,* Songqin Liu*

Jiangsu Engineering Laboratory of Smart Carbon-Rich Materials and Device, School of

Chemistry and Chemical Engineering, Southeast University, Nanjing 211189, China.

\section{Table of content:}

S1 Results

S-2

S1.1 Characterization of bisphenol ligand

$\mathrm{S}-2$

S1.2 Optimization of PCP NPs synthesis

S-4

S1.3 Characterization of materials

S-5

S1.4 Cell membrane extraction

S-8

S1.5 PCP NPs in different pHs

S-9

S1.6 OD values of fluorescence and CLSM images of materials

S-10

S1.7 FCM analysis

S-13 
S1 Results

S1.1 Characterization of bisphenol ligand
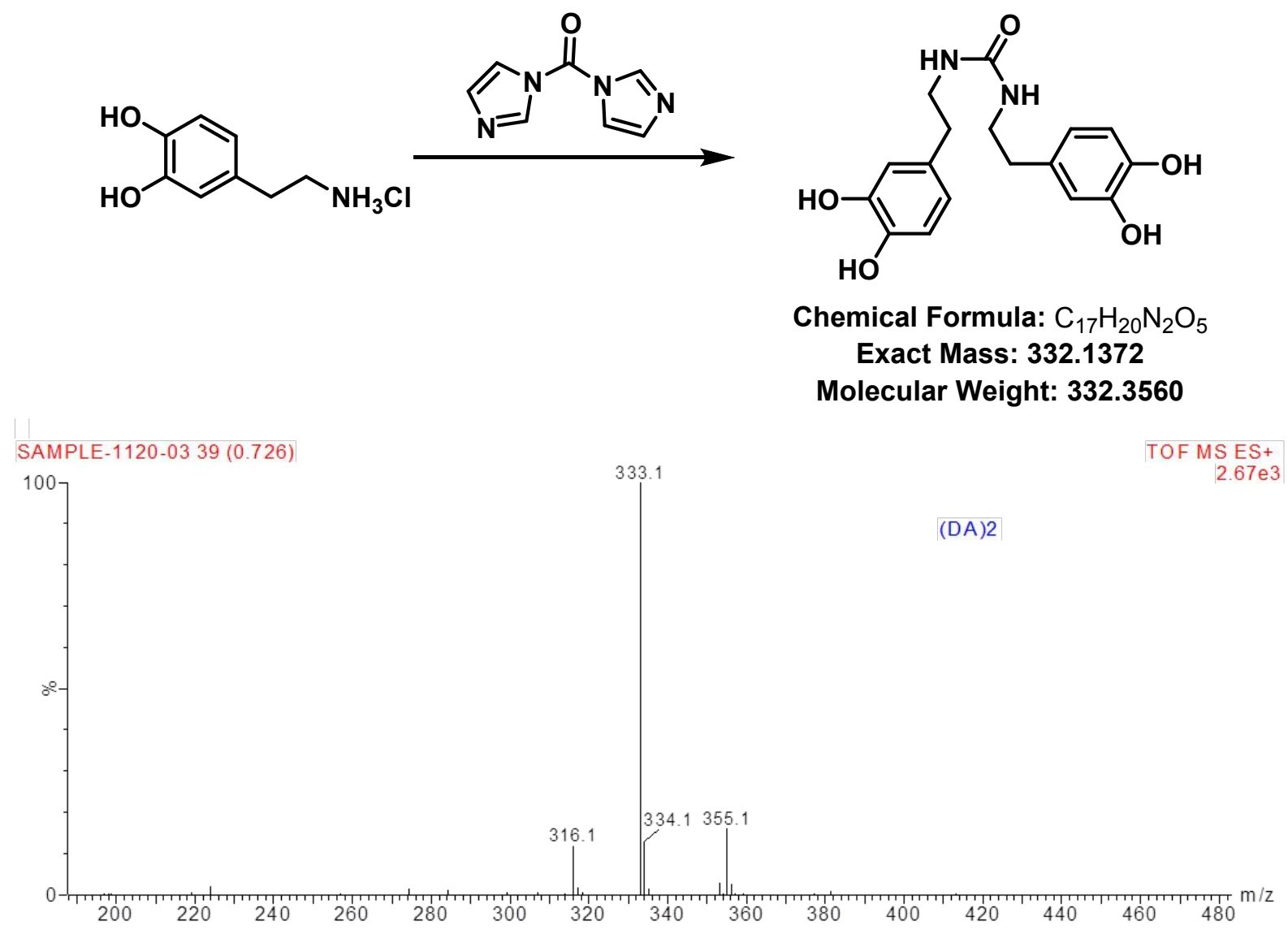

Figure S1. Mass spectrum of polyphenol ligand. 


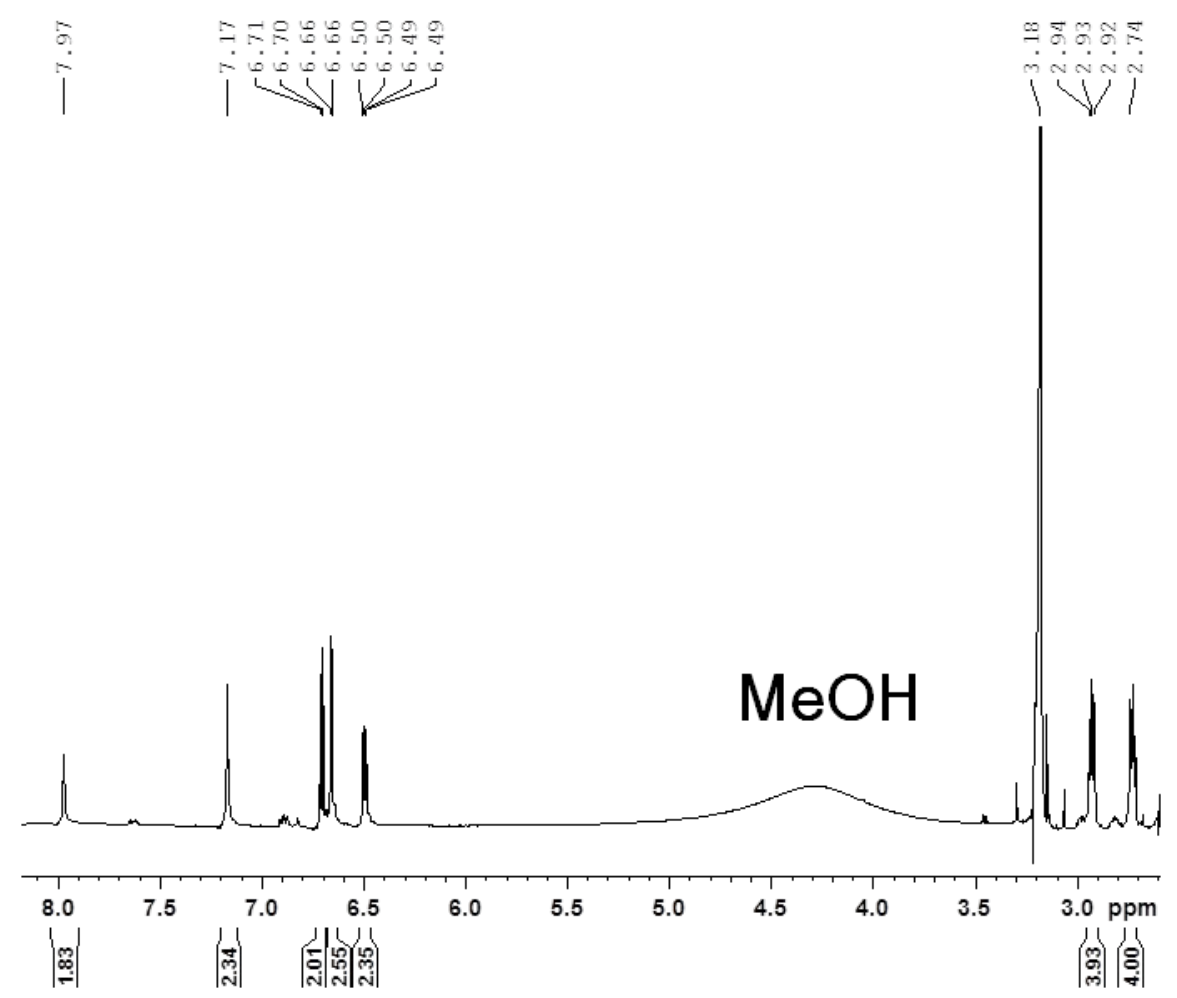

Figure S2. ${ }^{1} \mathrm{H}$ NMR spectrum of polyphenol ligand. 


\section{S1.2 Optimization of PCP NPs synthesis}

Table S1. Optimization of the ratio of polyphenol ligand to dopamine and the amount of PVP in PCP NPs synthesis.

\begin{tabular}{cccccc}
\hline No. & $\begin{array}{c}\text { Ligand } \\
(\mu \mathrm{mol})\end{array}$ & $\begin{array}{c}\text { Dopamine } \\
(\mu \mathrm{mol})\end{array}$ & $\mathrm{FeCl}_{3}(\mu \mathrm{mol})$ & $\begin{array}{c}\text { Aqua ammonia } \\
(\mu \mathrm{mol})\end{array}$ & PVP (mg) \\
\hline $\mathrm{a}$ & 15 & 0 & 10 & 14 & 0 \\
$\mathrm{~b}$ & 15 & 0 & 10 & 14 & 0.6 \\
$\mathrm{c}$ & 12 & 6 & 10 & 14 & 0 \\
$\mathrm{~d}$ & 12 & 6 & 10 & 14 & 0.6 \\
$\mathrm{e}$ & 9 & 12 & 10 & 14 & 0 \\
$\mathrm{f}$ & 9 & 12 & 10 & 14 & 0.6 \\
\hline
\end{tabular}
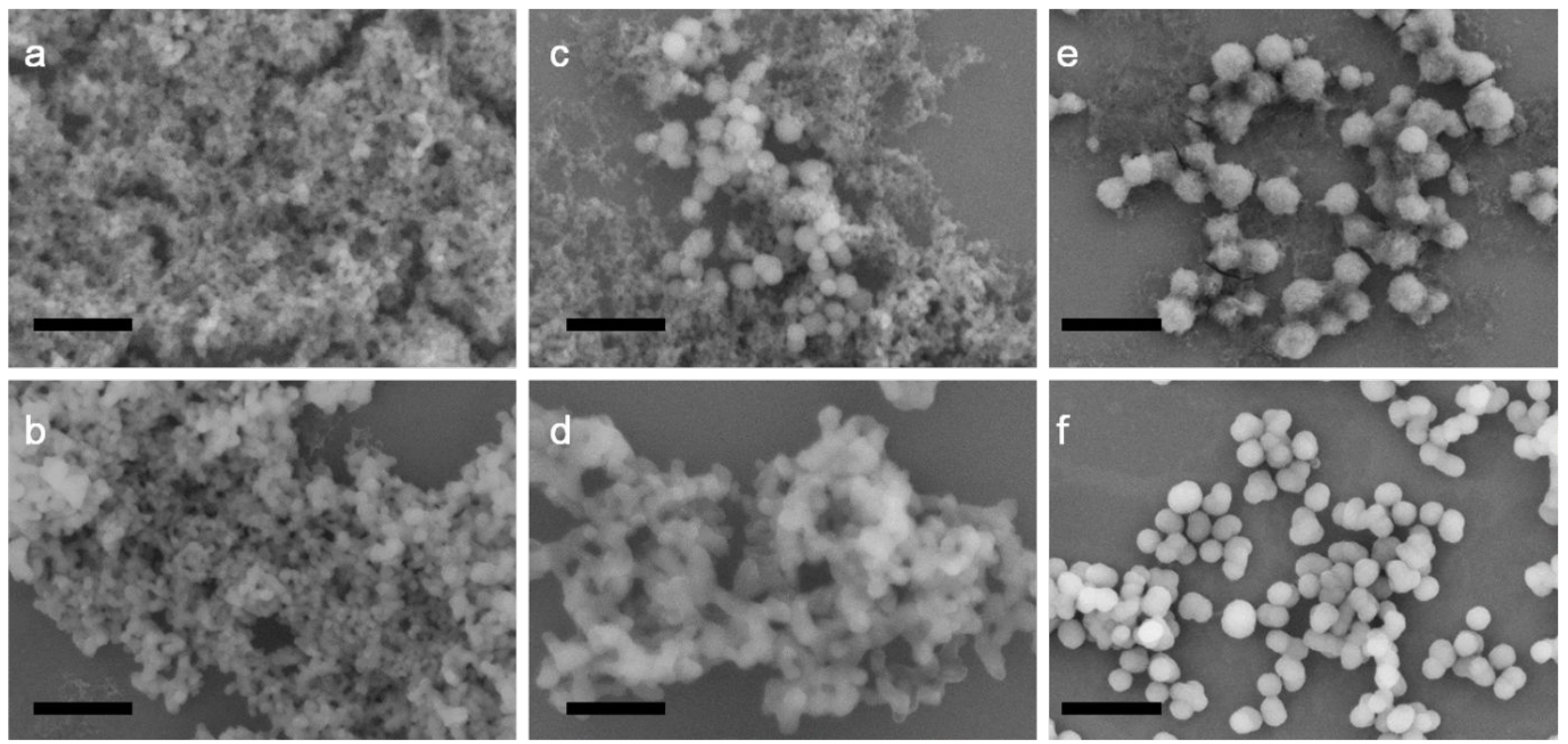

Figure S3. SEM images of PCP NPs synthesized under different conditions corresponding to the Table S1, scale bars are $1 \mu \mathrm{m}$. 


\section{S1.3 Characterization of materials}

Table S2. Element analysis of PCP NPs by EDX spectroscopy.

\begin{tabular}{ccc}
\hline Element & Weight \% & Atomic \% \\
\hline$C K$ & 76.10 & 83.90 \\
$N K$ & 04.80 & 04.60 \\
$O K$ & 11.70 & 09.70 \\
\hline
\end{tabular}

Table S3. BET analysis of PCP NPs and DOX loaded PCP NPs

\begin{tabular}{lcc}
\hline & PCP & PCP-DOX \\
\hline Surface area $\left(\mathrm{m}^{2} / \mathrm{g}\right)$ & 99.594 & 84.502 \\
Total pore volume $(\mathrm{cc} / \mathrm{g})$ & 0.530 & 0.381 \\
Average pore size $(\mathrm{nm})$ & 2.897 & 2.897 \\
\hline
\end{tabular}




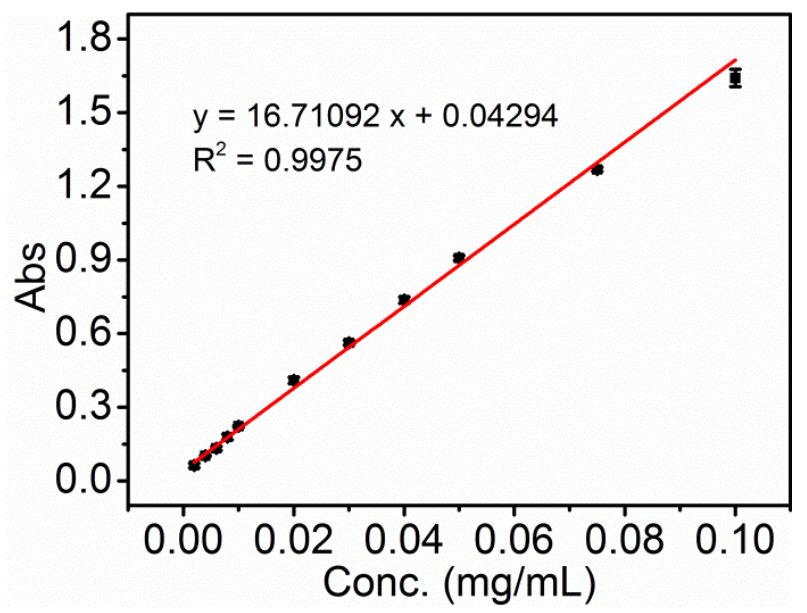

Figure S4. Working curve of DOX concentration against UV-vis absorption at wavelength of $500 \mathrm{~nm}$. 
a

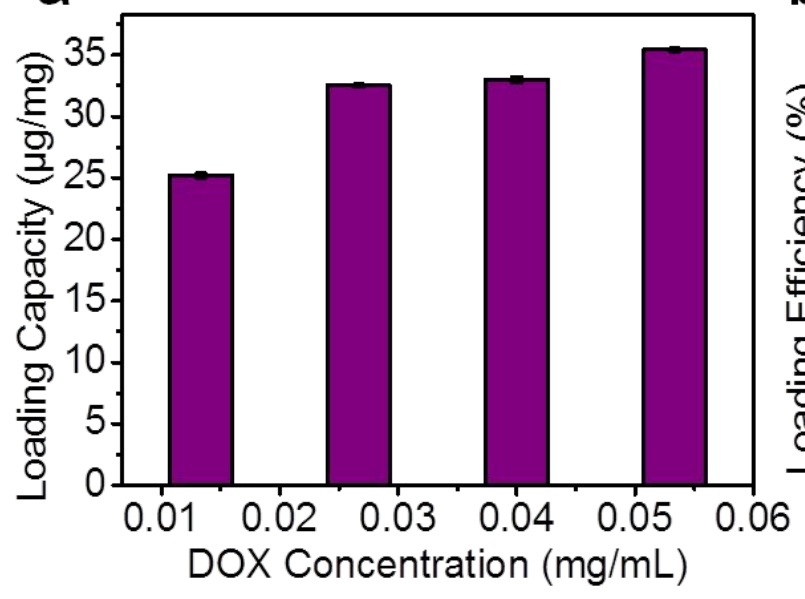

b

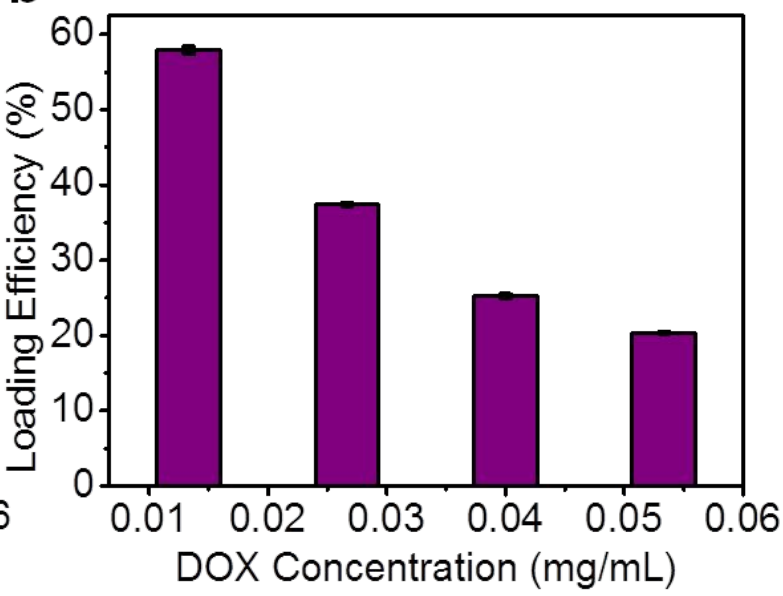

Figure S5. Optimization of DOX loading capacity (a) and DOX loading efficiency (b) in PCP NPs synthesis. The DOX loading capacity always increases along with the increase of concentration of DOX loading buffer while the DOX loading efficiency always decreases along with the increase of DOX concentration. 


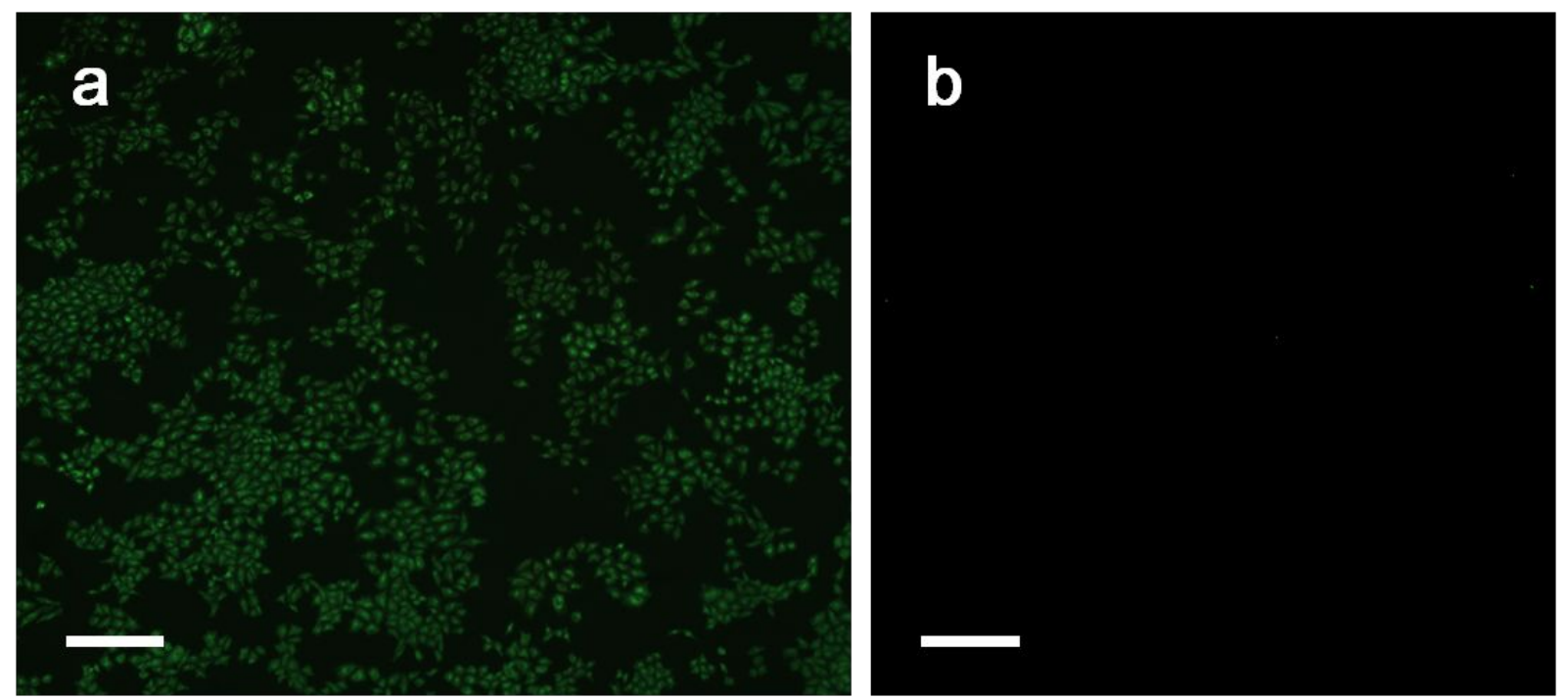

Figure S6. (a) DiO dyed Bel-7402 cells for homologous targeting investigation visualized by fluorescent microscopy, scale bar is $150 \mu \mathrm{m}$; (b) CLSM image of DiO labeled PCP, scale bar is $20 \mu \mathrm{m}$. 
S1.5 PCP NPs in different pHs

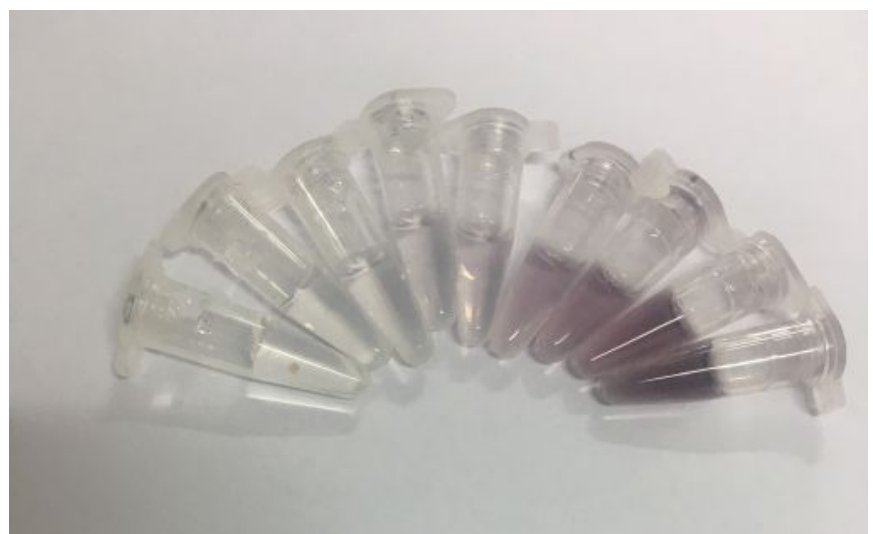

Figure S7. Samples of PCP NPs in different pHs. The pHs are 4.0, 4.5, 5.0, 5.5, 6.0, 6.5, 7.0, 7.5 and 8.0 from left to right, respectively. 


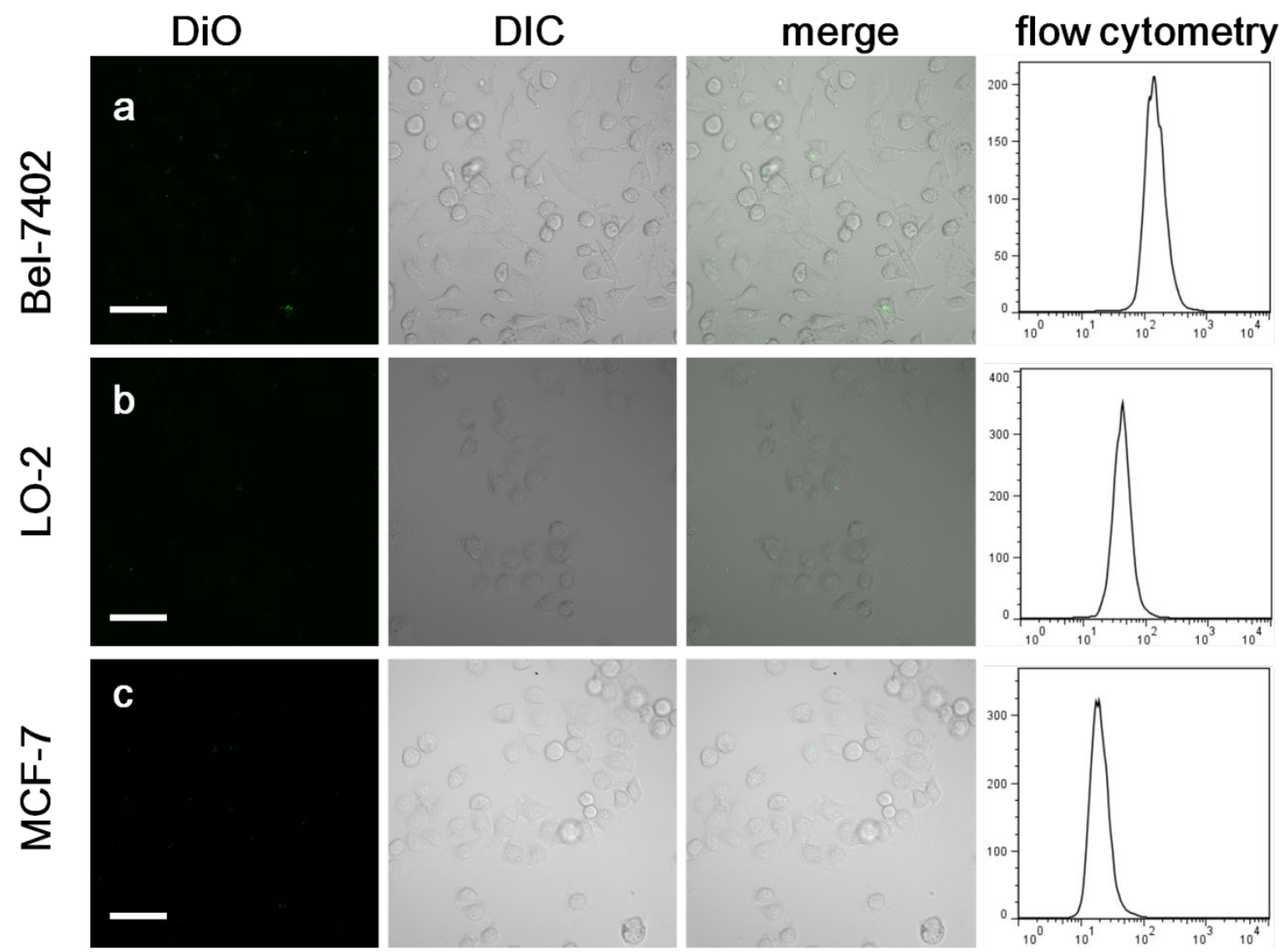

Figure S8. CLSM and flow cytometry analysis of homologous targeting behavior of DiO labeled PCP-CMs in Bel-7402 (a), L-O2 (b) and MCF-7 (c) cells, all cell lines were treated with $40 \mu \mathrm{L}$ of probes $\left(1 \mathrm{mg} \mathrm{mL}^{-1}\right)$ for $1 \mathrm{~h}$. Probes tend to accumulate more in Bel-7402 than L-O2 and MCF-7 cells. Images are listed as $\mathrm{DiO}$, the differential interference contrast (DIC), the merge channels and the flow cytometry from left to right, scale bars are $40 \mu \mathrm{m}$. The X-axis and Y-axis of flow cytometry are the fluorescence intensity of $\mathrm{DiO}$ and the count number, respectively. 


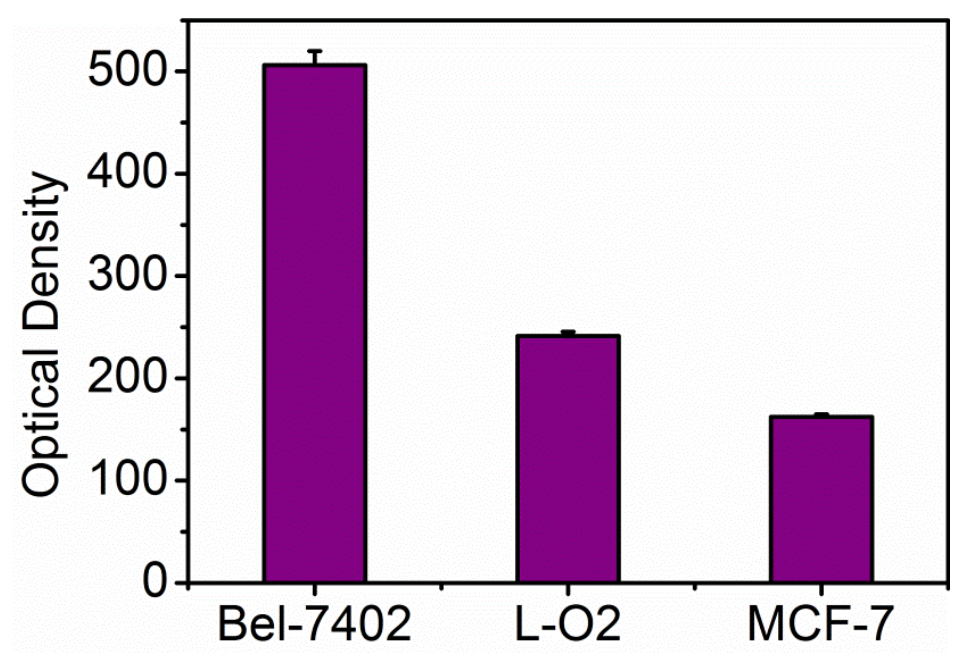

Figure S9. OD values of fluorescence in DiO channel of Bel-7402, L-O2 and MCF-7 cells in Figure S8, read by Image Pro Plus software. 


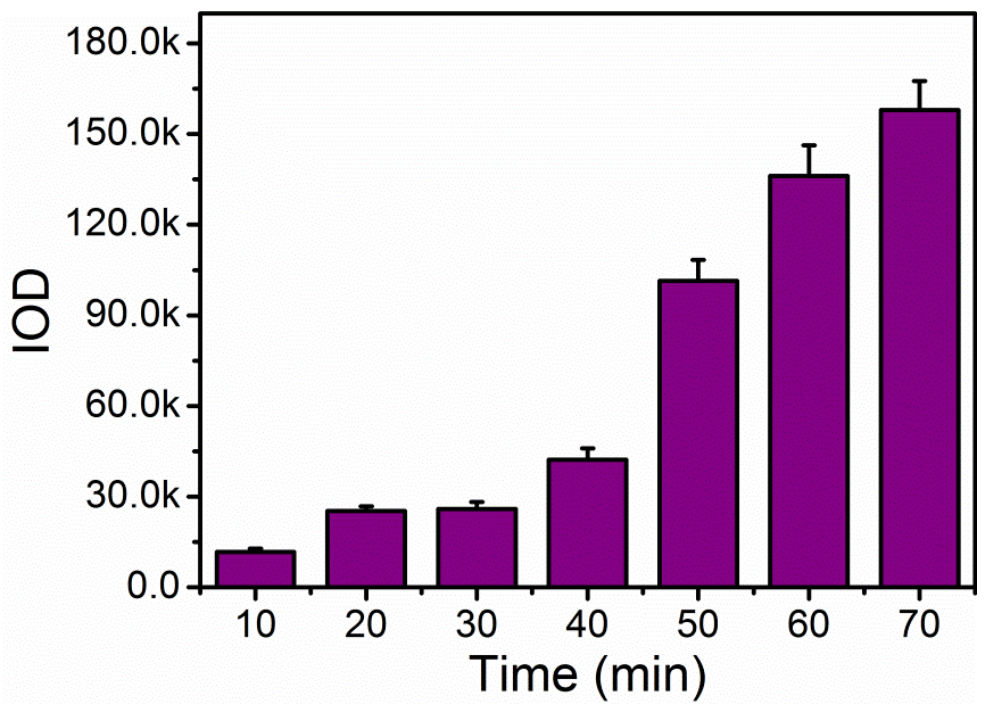

Figure S10. OD value changes of fluorescence in DOX channel of Bel-7402 cells incubated with $40 \mu \mathrm{L}$ PCP-DOX-CMs $\left(1.0 \mathrm{mg} \mathrm{mL}^{-1}\right)$ during $70 \mathrm{~min}$. 


\section{S1.7 FCM analysis}

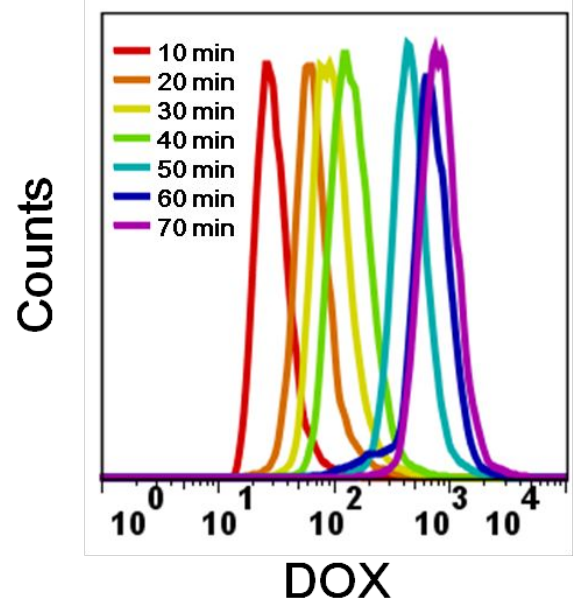

Figure S11. Flow cytometry images of Bel-7402 cells incubated with $40 \mu \mathrm{L}$ PCP-DOX-CMs (1.0 $\mathrm{mg} \mathrm{mL}^{-1}$ ) during $70 \mathrm{~min}$ in DOX channel. 